\title{
Florian Elliker
}

University of the Free State, South Africa

University of St. Gallen, Switzerland

\section{P. Conrad Kotze, Jan K. Coetzee}

University of the Free State, South Africa

\section{Group Identity and Groupness: Student Experiences at University}

Abstract One of the key transformations South African universities have undergone in the past two decades is the increase of racial and ethnic diversity of their student bodies and academic staff. In this study, we seek to contribute to a better understanding of these transformation processes by presenting students' narratives of how they experience the interracial integration of student residences. We first address the potential groupist and essential underpinnings of ethno-racial identifications by situating our categories of analysis in a social-constructivist framework, underlining the situational and processual character of identifying and establishing "groupness," while simultaneously considering the obdurate quality habitualized ways of identifying may generate. We then present an overview of our sensitizing themes as they are discussed in the literature on race and ethnicity with a focus on South Africa and student experiences. Thirdly, the article introduces the reader to the institutional context of the case study, namely, the campus of the University of the Free State and its studen residences. Based on focus group discussions and thematic analyses, we present our findings in the form of the cultural themes that are central to the students' narrations of their experiences. These themes include the salience of racial and ethnic identifications, tolerant distance, confusion, fairness, neutrality, ethnolinguistic recognition, regional public arenas, rural-urban divides, as well as socio-economic divides

Keywords Race; Ethnicity; Transformation; Narrative Studies; Groups; Identity Focus Groups

Florian Elliker is a Research Fellow in the program The Narrative Study of Lives, Department of Sociology, University of the Free State, Bloemfontein, South Africa. He is also a Senior Lecturer in the Institute of Sociology, University of St. Gallen, Switzerland.

email address: florian.elliker@unisg.ch

P. Conrad Kotze is a Lecturer in the Department of Sociology, University of the Free State (Qwaqwa Campus), and a PhD candidate in the program The Narrative
Study of Lives. He obtained his Master's degree in this same progran.

email address: kotzepc@ufs.ac.za

Jan K. Coetzee is a Senior Professor of Sociology and Director of the program The Narrative Study of Lives in the Department of Sociology at the University of the Free State Bloemfontein, South Africa. He specializes in qualitative sociology and serves on several international advisory boards. email address: coetzeejk@ufs.ac.za $\mathrm{n}$ this article, we present a focused interpretive sociological analysis of students' experience of transformation on a South African university campus revolving mainly around the closely intertwined phenomena of race, ethnicity, and groupism. The data have been collected since 2011 in the form of narratives generated by means of group interviews and participatory observation. The context of this article, being situated against the backdrop of South Africa's historical transition to a non-racial democracy and especially informed by institutional attempts at "integrating" groups of individuals who were historically segregated, may offer insights into future issues faced by European universities coming to terms with the increasing concrete results of multiculturalism. The analysis presented in this article is not aimed at furthering a given agenda or supporting any predominant opinion regarding matters of socio-cultural transformation, but simply aims to investigate the ways in which the people who find themselves subjected to these policies experience their ramifications on an everyday level. As such we primarily analyze the students' experience of group identity as constructed by themselves, as well as the interactions between these "groups." In the first section, we lay out the conceptual background underlying the analysis carried out during this study. The next section presents an informative overview of issues of transformation and diversity on university campuses as offered by existing research in this sphere, while the third section investigates the specific case of the University of the Free State. The fourth section presents the methodological framework put into practice during data collection and analysis, while some of the findings of the study are explored in the fifth section. The study was carried out under the auspices of the program The Narrative Study of Lives, of which Jan K. Coetzee is the director. Coetzee provided insight into narrative research on issues of transformation, risk, and uncertainty, as well as editorial input. Florian Elliker constructed the theoretical framework through which the analysis was approached, while Conrad Kotze developed the methodological framework, collected the data, and edited the final manuscript.

\section{Groups and Group Identity}

This article aims at reconstructing and analyzing how people who are affected by change experience transformation in their everyday life. In South Afri$\mathrm{ca}$, the process of transformation is officially aimed at improving the lives of historically disadvantaged "groups" and at improving "intergroup" relations. However, when studying social phenomena pertaining to race, ethnicity, and nationality-which are in many ways closely related domains and fields of analysis (Brubaker, Loveman, and Stamatoy 2004:47; Brubaker 2009)-the concepts "group" and (group) "identity" appear to be problematic. In this article, we do not view racial (or ethnic) "groups" and "identities" as merely given, but as embedded in socially shared meaning-frameworks additionally informed by subjective experience and socially contextualized understanding. Thus, the experience of "intergroup" relations on a university campus and the students' narrative accounts thereof are likely to be structured, from a sociological perspective, by two contexts: local intersubjectively established ways of (non-)ethnicized or (non-)racialized interpreting and acting, and historically informed 
cultural patterns of interpretation and action. These contexts have a bearing on how students experience transformation and on what they perceive to be relevant to and characteristic of the process of transformation. They are, firstly, actual contexts that the students have encountered before and during their life on the university campus. Secondly, they have contributed to the intersubjectively constructed meaning-frameworks that inform students' interpretations of current and past experiences.

Although "racism" is generally regarded as undesirable and even illegal, the mundane discursive space in South Africa is still dominated by highly objectified notions of race and ethnicity. This section therefore serves not only to outline our analytical apparatus, but also to reformulate our object of analysis-"intergroup" relations-from a social constructivist perspective. While the empirical analysis itself is based on the data collected in focus group sessions with students, we outline the relevant dimensions of their everyday life-the ethnographic context-in social constructivist terms. In the South African context, which is burdened with a history of racialized segregation and exclusion with dire consequences for the vast majority of the population, it is important to remember that a social constructivist perspective does not deny the reality of racism and its consequences. It merely aims to study this reality in a specific way by highlighting those aspects of reality that are intersubjectively constructed, maintained, and transformed, or what Conrad Kotze (2017) calls the intersubjective etiological dimension. A common misreading of the social constructivist perspective in the tradition of a sociology of knowledge approach is that it allegedly denies the resilient and structured character of social reality. The current analysis explicitly counters this accusation, arguing that much of social reality's seemingly solid and obdurate character is a consequence of institutionalization processes. The reality of race and racism is therefore not the result of an "essential" nature of individuals or populations, but of institutionalized social practices that have the effect of reifying "groups" and "identities" that are experienced as objectively given by the individual operating from within the natural attitude.

The nature of present experience is shaped by past experiences that have coagulated into a subjective stock of knowledge, which is structured by types and typified relations, along with systems of thematic, interpretational, and motivational relevancies (Schütz and Luckmann 1989; Schütz 2004). Experience plays a crucial role in individual interpretation and informs both the content of intersubjectively constructed meaning-frameworks and their correlating patterns of social interaction. In its habitualized forms, this stock of knowledge provides a background of routine action and interpretation that does not warrant explicit attention by the subject operating from within the natural attitude. This enables members of a society to engage in "focused" action without having to renegotiate taken-for-granted issues through moment-to-moment reappraisals. A large part of the individual stock of knowledge is intersubjectively constructed and passed on to the individual, making it historical in origin and ensuring that, over time, pragmatically efficient patterns of interpretation and interaction are habitualized, externalized, institutionalized, and legitimized. In this way, by means of an ongo- ing process of communication and mutual understanding, a seemingly objective reality that the individual is confronted with takes shape out of an essentially arbitrary sequence of meaning-ascription (Berger and Luckmann 1966).

Thus, although fleeting and dependent on human reproduction, social reality is locally objectified and comes to inform (and often dominate) the experience of the socially embedded individual. In this sense, the structure of social reality emerges from routinized, habitualized, and institutionalized patterns of (inter)action and interpretation. On the one hand, actions create a context reflexively (Gumperz 1982). This means that the social situation is defined by the very act of engaging in certain practices and therewith stimulating the corresponding notions of propriety and ways of reaction among those engaged in these practices. Individuals' socially derived knowledge of these practices tends to reproduce social reality in typical ways-thus the structure of social reality also pertains to the distribution of knowledge needed to meaningfully engage in these practices. On the other hand, (inter)actions are enmeshed within a nexus of objectified meaning-frameworks that seem-from the perspective of the socialized individual operating from within the natural attitude-to be given in the empirical sense, as phenomena existing beyond individual agency. Hence, social reality is routinely experienced as consisting of different actors engaged in institutionalized routines that the individual subject is only able to bypass at the risk of having his/her own actions subjected to intersubjectively reified expectations. From the perspective of the individual, social structure thus also pertains to the unequal distribution of access to certain social situations, groups, and institutions, or various "arenas" which become accessible to the individual only by means of the internalization of relevant aspects of the dominant stock of knowledge and repertoire of action patterns.

Each of these structural contexts is connected to a conglomerate of knowledge and typical actions. Throughout this article we use the term culture to distinguish such broad conglomerates of knowledge and practices from each other. Culture in this sense pertains not specifically to those higher orders of knowledge encompassing art, religion, science, and law, but to all knowledge and practices that are needed to cope with everyday life. Culture therefore generates a paramount reality according to which any given individual is oriented. It does not only refer to a symbolic realm, but to the "intimate link of knowledge and action, of 'cognitive system' and 'social organisation'”' (Knoblauch 1995:73). Thus, culture denotes conglomerates of empirically distinguishable ways of action, interpretation, and knowledge that are bound to and typical not only of specific social situations, groups, organizations, entire institutional realms, and milieus, but also of social categories (this entails, for example, organizational cultures or professional/vocational cultures). Cultural practices may be institutionalized in varying degrees and encompass more or less objectified expectations of what the appropriate ways of (inter)action and interpretation are within the specific contexts. It is important to note that the term culture neither pertains exclusively to ethnicity or race nor entails essentialist notions, that is, the notion that the sharing of ideas and practices inherently leads to or forms an existential unity of the involved actors. Individu- 
als are always simultaneously participating as actors in several cultures; in the cultures of their organizations and professions, peer groups, sport teams, and families, et cetera. In this way, a significant part of their experience is informed by "cultural interferences" (Reckwitz 2001) stemming from the diverse interactions between the "cultural grammars" of the various cultures that they are involved in. As these interferences may be mutually relativizing, individuals may develop a sense of agency by critically reflecting upon intersubjectively constructed meaning-frameworks in thought and in action. Our aim is neither to denigrate the existential agency of the individual subject nor to deny the existence of objectively given quanta and qualia, but to explore in greater detail specifically those aspects thereof that arise on the basis of intersubjective meaning sharing.

In the context of experiences pertaining to ethnicity and race, the concepts of "group" and "identity" often serve as categories of political practice and analysis. Both terms are used by both "lay" actors and by political actors to make sense of and frame their activities and their self-understandings and to organize and legitimize the pursuit of their interests. But, as both terms refer to collectivities encompassing a large number of people, they are likely to entail essentialist notions that cannot be unproblematically generalized. Pertaining to "groups," one cannot simply presuppose "single, bounded groups as basic constituents of social life, as main protagonists of social conflicts and as fundamental units of social analysis" (Brubaker 2002:164)-a notion that Rogers Brubaker has called "groupism." Conceived in such a way, "groups" are seen as monolithic and homog- enous entities endowed with agency used for pursuing the common goals of its members. This corresponds to the use of identity as an assumed "fixed" or "strong" self of the individual that is seen as being the result of belonging to a specific group, the individual being endowed with particular group-specific "features" and interests. Such "strong" notions are potentially powerful political instruments, and are often used by politically motivated actors who deploy them to achieve certain goals, either against or in the name of and avowedly for certain "groups" with specific "identities." While many "groups," especially pertaining to race and ethnicity, are identifiable by their obduracy across time and space, solely focusing on the historical manifestation of such groups and their interrelationships may contribute to the generation of social realities wherein essentialist notions are objectified to such an extent that there is hardly any discursive space for alternative perspectives. Thus, research that employs categories of political practice uncritically as categories of analysis runs the danger of reifying social reality in problematic ways. To avoid contributing to this impasse, we employ categories from an alternative set of analytical concepts. For the analysis of the narrative accounts of the students, we make use of the distinction between relational and categorical modes of identification. The former pertains to identification "by position in a relational web (a web of kinship, for example, or of friendship, patron-client ties, or teacher-student relations)," while the latter is used to indicate "membership in a class of persons sharing some categorical attributes (such as race, ethnicity, language, nationality, citizenship, gender, sexual orientation, etc.)" (Brubaker and Cooper 2000:15).
Identification is a situated and context-dependent process. While some categorical identifications may differ from situation to situation, others are more persistently engaged across contexts. Individuals identify themselves and others while constantly being identified by others in their turn, while self-identification and the ascription of identity by others are not necessarily congruent. Thus, categorical identifications that are applied to large portions of populations do not simply constitute "groups" in the sense of collectivities experienced as meaningful by those constituting them, but merely sort individuals into tentative "pre-group" collections (Bowker and Leigh Star 2000). Under certain circumstances, categorical identifications may take on group-like qualities that we analytically separate into commonality, connectedness, and groupness (Brubaker and Cooper 2000:19). In this context, "commonality" denotes the sharing of some common attribute, while "connectedness" denotes the relational ties that link people. Neither commonality nor connectedness alone engenders "groupness"-the existentially meaningful sense of belonging to a distinctive, bounded group, but commonality and connectedness together may indeed do so (Brubaker and Cooper 2000:20). In the case of large collectivities, it is unlikely that connectedness is needed to create an intense feeling of belonging together; rather, groupness may be created by evoking powerful feelings of commonality. This crystallization of vague and diffuse identifications into a strong sense of belonging to a bounded group is a process that depends on the mapping of particular events onto discursively shared meaning-frameworks.

In contrast to the notion of "large groups," we use the term group to denote relatively small groups, constituted by repeated, often highly patterned, interaction of reciprocally related actors. The prevailing patterns of their interaction are in turn shaped by a shared culture, founded on a common nexus of intersubjectively constructed meaning-frameworks rooted in a shared history. Groups establish and maintain boundaries, routinely distinguishing between members and non-members. Groups are situated in an arena, a physical or virtual space that they depend on for their enactment. They remain relatively stable through adjusting "lines of action" (Fine 2010:367) and routine "interaction ritual chains" (Collins 2004). Group culture thus refers to "those sets of meaning that are tied to a recognisable interaction scene and its routine participants" (Fine 2010:356). The culture of the group, reflecting a host of past shared experiences which are remembered in a shared "narrative repertoire" (Frank 2012), sets standards for propriety and action, forms a basis of collective representation, and codifies an "interactional grammar" (Fine 2010:366). Its structure results in practices building on previously sedimented routines, and is thus relatively stable. In the routine existence of a group, transformation is likely to consist of incremental change. More fundamental changes are likely due to external pressures or unpredicted events that facilitate a renegotiation of group culture and identity. New members being socialized into the group culture are a potential source of this kind of upheaval. Depending on how strong or weak their affiliations with the group become, they are existentially engaged in the group to various degrees, internalizing the life-worldly standards of the group culture to a greater or lesser extent and hence also contributing to its reproduction 
and change in different ways, and informing their self-understanding accordingly.

Groups do not exist in isolation, but are connected to other groups both through sanctioned patterns of relatedness and through the multiple group memberships of any given individual. This gives rise to institutional realms in which specific groups are further connected by means of corresponding institution-wide communication, and embedded in an ecology of groups with differentially distributed authority and access to resources. The groups constituting such an ecology are also rooted in diverse matrices of socially shared meaning-frameworks. Organizational decisions are made within small groups and spread to other micro-publics through an established hierarchy of group relations. As "tiny publics" (Fine and Harrington 2004), they are not only the basis of organizations, but as "small communities of interest and experience, [they] provide the basis of civil society as they are where politics is discussed and enacted" (Fine 2010:361). Groups are internally segmented and may control access to membership more or less strictly, with boundaries being established by informal criteria and/or institutionalized categories. Thus, "through maintaining boundaries, local settings become the site for exclusion or segregation, suggesting why members of social categories have differential access to knowledge, resources, or relations" (Fine 2010:359). In the following section, we will take a preliminary look at the ways in which various groups relate to one another, based on a survey of studies dealing with the issues of importance to our analysis.
Race, Ethnicity, and Groupness in South Africa and the World

Studies on race and ethnicity, ${ }^{1}$ long fragmented along national, disciplinary, and paradigmatic boundaries, are slowly emerging into a "new field that is comparative, global, cross-disciplinary, and multi-paradigmatic, and that construes ethnicity, race, and nationhood as a single integrated family of forms of cultural understanding, social organization, and political contestation" (Brubaker 2009:22). Ethnicity and race have been studied in connection to the active use of ethnic and racial notions in the pursuit of collective goals, thus examining the relationship between nation states and ethnic mobilization (Olzak 1983) and between ethnic entrepreneurship and the group's cultural characteristics and access to resources (Aldrich and Waldinger 1990). Ethnicity has further been analyzed in relation to social stratification and discrimination, in terms of culture, and how it links up with politics (Yinger 1985), and in the context of conflict (Williams 1994) and ethnic and nationalist violence (Brubaker and Laitin 1998). Much of this research has been international and comparative. Ethnicity has also been examined in terms of its links to state formation, nation building, and nationalism. Despite increased international mobility, "neither nationalism nor ethnicity is vanishing as part of an obsolete traditional order...Nationalism, in particular, remains the pre-eminent rhetoric for attempts to demarcate political communities, claim

${ }^{1}$ The term race is popularly used to refer to distinctions between populations based on physical appearance, while ethnicity refers to distinctions between human populations based on various cultural variables (Frable 1997). rights of self-determination and legitimate rule by reference to 'the people' of a country," while "ethnic solidarities and identities are claimed most often where groups do not seek 'national' autonomy but rather a recognition internal to or cross-cutting national or state boundaries" (Calhoun 1993:211). Racial and ethnic ways of imagining communities have involved processes of substantialization that are often reproduced by social scientists (Anderson 1983; Alonso 1994). Ethnicity and race have been part of the making of national cultures, that is, part of how "national culture [is] rendered as an implicit, taken-for-granted, shared national habitus" (Foster 1991:237). Research has been carried out on how ethnicity serves as a resource in creating social boundaries and groups (Sanders 2002), and there has also been a focus on the intersection of sexuality and ethnicity indicating that ethnic, racial, and national boundaries often overlap with sexual boundaries (Nagel 2000). Attention has been given to ethnicity and gender related attitudes and inequalities (Kane 2000), as well as to the persistence of racial prejudice and discrimination in general (Quillian 2006). There has also been differentiation between ethnicity and race and a focus on the enduring power of the latter (Harrison 1995), for example, in processes of residential segregation (Zubrinsky Charles 2003). A good deal of research has dealt with the macro level, analyzing race as racial formation (Omi and Winant 1994) or as race discrimination system (Reskin 2012). As much research on race, ethnicity, and nation involves rather large "collectives," such "macro"-level investigations implicitly often evoke groupist notions (cf. Brubaker 2002). "Group" is, however-as discussed in the first section-a problematic concept for such large communities of people as its use may contribute to the substantialization of these very groups instead of analyzing the social processes that generate feelings of groupness associated with the corresponding population categories.

Sociological work on race and ethnicity in South Africa specifically has been diverse. Apartheid legislation incorporated a racialized perspective in many societal realms, and as the ensuing racialized social realities still indicate a cloven society (Prinsloo 1996), the concepts of race and ethnicity are at least implicitly present in much social scientific research. This is also true in work that is not mainly concerned with race and ethnicity, as in research on poverty and development (Wale and Foster 2007), elite attitudes (Kotzé 1993), work values (Steyn and Kotzé 2004), and the life satisfaction of students (Møller 1996), as well as in the sociology of work (Webster 1999). Empirical work has dealt with race and ethnicity in relation to most social realms, among others in connection with citizenship (Klugman 2008), racial relations at White universities (Gwele 2002), linguistic diversity and identity politics (Venter 1998; Kriel 2003), racialized and (de)segregated places (Piper et al. 2005; Peens 2012), and racial stereotypes (Vahed 2001). The occurrence of (small) groups built around racial and ethnic categories thus remains a characteristic of society in general and of South African society in particular. We argue that the reason for this is not explicitly political in as much as the continued existence of these groups is cultivated not only by organized social institutions, but primarily by the meaningful interpretation and consequent patterns of behavior of people going about their daily 
lives. Factors linked to race and ethnicity are deeply internalized and correlate with readily observable facts of perception that seem empirically given, thus carrying over this objectified nature into tangible consequences on patterns of social interaction. With this in mind, we now turn our attention to the specific ways in which these realities seem to impact students worldwide and especially in such a culturally diverse society as South Africa.

Many of the students we interviewed experience their everyday life on campus as shaped by socializing in small groups along racial categories. To move outside of these boundaries is not without impact on their daily lives; for example, they may risk to lose contact with their in-group, as studies show for African American students who chose to adapt themselves to the dominant White American culture in one study (Arroyo and Zigler 1995). While rhetorically professing respectful attitudes to members of all racial categories, students simultaneously confess to forming racial and ethnic enclaves within the broader student body. In such circumstances, social intercourse across racial and ethnic categories may be limited to the extent that it is almost negligible, as has been confirmed by various studies on student self-segregation carried out in the United States (Taylor 2011). Although there are many parallels to be seen in South Africa as students tend to categorize themselves like their international counterparts do, they do so in slightly different ways and under the specific historical and demographical circumstances of the South African society, complicating not only the conventional Black-White dichotomy, but also the commonly used minority-majority distinction. In contrast to many other studies in the domain of acculturation and so-called "intergroup" relations (e.g., Brown and Zagefka 2002; Sennett et al. 2003; Sang, Wang, and Zheng 2004; Brown and Greenland 2005; Chavous 2005; Cole and Yip 2008), the experiences of the participants of our study are not set in a predominantly White setting in which Black students constitute also demographically a minority. While in terms of material wealth and economic power the White population segment remains privileged, it demographically constitutes a minority of South Africa's population and thus lacks political power as a bloc, faced with the challenge of becoming a minority (Alsheh and Elliker 2015). Research on South African university students found, for instance, that White students expect their economic position relative to Blacks to suffer over the next decade, while the Black students expected to gain ground relative to Whites, but still come up short in ten years' time (Dumont and van Lill 2009). In a study measuring the adjustment of Black students at the University of Johannesburg, a historically White university comparable to the University of the Free State, it was found that levels of social, personal, and institutional adjustment related to race were closely linked to eventual academic performance (Sennett et al. 2003). Ethnic and racial categories are not only implied in the distribution of material wealth and political power, but intersect with an array of other issues, among others discrimination based on sexuality, gender, and religion (cf., e.g., Bishop et al. 2004; Ehrmann 2007), but also issues of psychological health (Arroyo and Zigler 1995), well-being, and academic performance (Liem and St. Louis 2005), as well as broader cultural changes such as postmodern stances impacting the experiences of the students (Dietz et al. 2005)-all themes related to by the participants of our study. These changing intersections all have an impact on the transformation process on the university campus with regard to how students relate to each other in terms of ethnic and racial identifications, much of which is still shaped by student self-segregation (Crozier and Davies 2008).

The Case of Life on the Main Campus of the University of the Free State

When students access any university campus, they enter a large and diverse arena of action, constituted by a multiplicity of more or less strongly bounded groups of various sizes. Their experiences, actions, and interpretations within this arena are in many ways implicitly or explicitly related to these groups. The university is enacted through small and medium sized groups-work teams, departments, administrative units, student associations, sport teams, et cetera-all of which are linked to each other through bureaucratically institutionalized connectors typical of large organizations, as well as through more informal processes. An important spatial arena of the University of the Free State is the main campus in Bloemfontein, which is cordoned off from the surrounding city by fences and strictly controlled access gates. All but one of the participants' residences are located on this campus, interspersed between teaching venues, sports facilities, office buildings, parking areas, streets, and park-like lawns. Students living at residences become members of a group in the above outlined sense. The groups are clearly bounded (residents are regarded as members, all other persons as non-members) and have their own exclu- sive spatial arena (in addition to the public arenas of the campus) within the residence building. The residents participate in a web of relations within the residence, establishing in various ways ties to the group and engaging in various activities as members of the residence (e.g., participating in residence meetings, sporting competitions, etc.). The groups feature a more or less specific idioculture that is also shaped in activities that represent it externally. For instance, first year students engage in a parade contest, where members of different residences visit each other as a group and perform short plays. Most of the residences have a reputation pertaining to (excellence in) academics or sports, but also to the composition of its members pertaining to commonly perceived socio-cultural categories. At the time of our study, all residences were gender segregated, that is, inhabited exclusively by either male or female students.

Students are connected to other groups, an important one being their family. In some families, it is customary for the parents to visit the residence in the first year to see how their offspring is doing. They may also play a role in deciding whether the student will live on campus or not and in the process of choosing a residence. In some families, members of different generations have lived at the same residence. Among other relevant networks or social relations, students are likely to stay in contact with former school friends, some of them studying at the same university and often part of different residences and peer groups. Student life is not only experienced in groups, though; it may be experienced in relatively anonymous places such as cafeterias, libraries, offices of the university 
administration. In these contexts, the individual student and the staff adopt their context-dependent, institutionalized roles. During lectures the student role is usually experienced in a collective, but the collective does not necessarily form a bounded group with a specific group culture. Apart from being a spatial arena of and for diverse social situations and groups, the university campus and its institutions are also experienced as "university," as a unity that is presented symbolically. This is done by means of university wide communication, such as weekly newsletters from the vice-chancellor, a campus radio station, the university website, and through events and processes that are interpreted as pertaining to parts of or the entire university, the university logo being present in the spatial arena and in the aforementioned communication channels, but also in advertisements and promotional material of the university that appear in regional and national newspapers.

Within the residence, all students share certain duties and obligations (such as adhering to the house rules), participate in residence related cultural practices, and identify each other relationally as members of the residence. At the same time, students are categorically identified according to "seniority," for example, as a "first year" or "third year" student. In the residences' idioculture, these categorical identifications have practical implications. Freshman students generally do not share the same "rights and privileges" as second and third year students, have to endure forms of "orientation" during the first year, are sometimes seated separately in residence meetings, and do, mainly in residences for male students, often have to pass an "initiation" at some stage, a rite de passage whereby they become "full" members of the residences. Freshman students who do not reside in a residence are not confronted with these relational expectations and obligations. Through their enactment categorical identifications such as "first year student" may form the base for creating groups-in relation to the residence-or subgroups of students, their categorical commonality through shared activities being complemented by relatedness and potentially by feelings of more or less intense groupness (e.g., in the case of shared initiation rituals that are experienced as humiliating). While members of a residence may internally identify each other relationally as members (and interact accordingly), they may simultaneously be identified categorically by non-members of their residence, that is, as members of a certain residence, and be treated accordingly. For the individual, residence membership may be used in a categorical or relational mode of identification by another; life on campus does allow not only for categorical identifications being enacted in environments where students are also relationally identified, but relational identifications may also become categorical ones. Thus, there is a wide range of opportunities for non-ethnic or non-racial modes of categorical and relational identifications. The students' relations to each other and their self-understanding may be formed by adhering to the idiocultures of groups of which they are members, developing strong or weak ties to that group, relationally identifying others as members of the same group or identifying them or others with categories pertaining to university life.

It does also, however, create an environment where university related categorical or relational identi- fications are enacted in conjunction with racial or ethnic categories. In addition to stereotypical category-bound actions and interpretations, racial or ethnic categories can become entangled in group-related activities and may-as in the example of the "first year" student category-be complemented by direct relatedness. Thus, they potentially serve as the basis for a more or less strong feeling of groupness, concerning not only subgroups within residences or sport teams, but also intergroup friendships or networks. This is of particular relevance, since for some of the students, the campus and especially the residences are the first action arenas in their life-courses where interaction with people ascribed to other ethnic or racial categories has the potential of going beyond stereotypical category-bound patterns of action and interpretation. For the first time in many cases, these interactions take place over an extended period of time, in relatively intimate, non-anonymous settings (residences), encompassing working and playing relationships, sharing the same mundane activities, and involving relational and categorical identifications pertaining to other realms than race or ethnicity. In other words, the university campus may be the first action arena in their lives where certain latent culturally bound meaning-frameworks oriented towards racial or ethnic identifications could be enacted in such a way that actual feelings of groupness are created-enacting effective "intergroup" or "group" relations that are otherwise an unsuitable label for such broad population categories as the ones pertaining to race or ethnicity. Indeed, the amplification of the still often segregated and alienating nature of South African society in general in the arena of a historically Afrikaans university tends to result in highly polarized campus politics that rapidly serve to reify issues of race and ethnicity to a level that is seldom concretely experienced off campus. The degree to which such possible feelings of groupness constitute a novel-

ty for a particular student likely depends on his or her biography prior to the university, which is shaped through the belonging to various small groups such as the family, peer groups, et cetera. These experiences may differ with respect to how categorically segregated the group environments were in the students' biographies. The vast majority grew up in groups and graduated from primary and secondary educational institutions that were composed of members of mostly the same racial or ethnic category. Interaction with persons of other categories mainly took place in relatively anonymous settings, or "non-places" (Augé 1995), in spaces within which one does not become part of a distinct group-if such locations were mixed at all in that regard. Indeed, the students' narratives suggest that large parts of these realms are not "categorically mixed" either, but segregated.

The potential creation or amplification of feelings of groupness along ethnic or racial categories at the university campus may thus either be experienced as something new or as a continuation of one's segregated upbringing exclusively among groups consisting only of persons of one category, the latter, however, with the important novelty that the students at the university are formerly unknown "members" of the same category. Such a creation of groupness might even be more strongly related to the categorical identification, since in the prior lived experience, such identifications have 
most probably always been intertwined with other identifications. "Others" have also been, and most likely, have predominantly been family members, neighbors, peers, et cetera. This gives rise to the categorical identification serving as the only, or one of few, resource(s) available during the generation of such a feeling of groupness, which in turn makes the categorical attribute potentially more salient in its perceived "effectivity" of being a reason/base for bonding, for inclusion and exclusion. Whether ethnic or racial categories serve as a basis for feelings of groupness among members of the same category, it is an empirical question whether category membership alone is sufficient to generate such feelings. Most likely this is not the case, as it is not experienced as an abstractum, but amidst concrete settings with other relational or categorical expectations and obligations. The relevant difference pertains to what set of interpretations and practices are dominant in interaction; either those that are bound to the local residence culture and its relational network or those bound to the racialized categories. Residences might thus provide a potential arena for developing ties that go beyond racial categorical identifications, but might also be a place where racial identity and its social implications are enforced. Institutionally "mixing" residences is thus not a guarantee for the promotion of the former possibility, not least because the residence integration policy (which has failed in the past $)^{2}$ and the resulting creation of unbalanced presences of different ethnic or racial categories in a residence tend to make the categorical identification more salient than before.

\section{Data Collection and Analysis}

The findings presented in the fifth section concern only one of a whole range of realms that were subject to interventions by the university administration, such as activities of political parties on campus, substance use, gender relations, and religion. As students' perceptions and experiences concerning these issues did not crystallize into readily available "naturally occurring" data-that is, artefacts suitable for data analysis covering all these aspects-data were collected in focus group sessions. They involved "engaging a small number of people in an informal group discussion...'focused' around [the above outlined] set of issues" (Wilkinson 2011:168). They differed from "group interviews" in that there was no regular back-and-forth exchange between the researcher and the participants, but the researcher allowed for and encouraged interaction between the group participants (Morgan 1988:12). Used as a self-contained method, the main aim was to facilitate detailed representations about the issues of interest (Bohnsack 2004:220), the points of views mainly stemming from the discussion among the students. The students' interaction generated enriched and nuanced accounts of typical experiences and brought to the fore in more explicit terms differing views in relation to contested issues (Warr 2005). The students' narratives were analyzed primarily with regard to their perspectives concerning the abovementioned issues.
Interested in what way the students used to make sense of their experiences, we pursued a thematic approach to the focus group data (Silverman 2011), analyzing which domains, categories, and themes structured the views of the students. This first reading suggested an additional reading, as the accounts of experiences often referred to local cultural contexts with relatively autonomous systems of relevancies and action problems that can selectively become a stage for the enactment of population categories. Thus, the data were also read as an ethnographic account to tentatively describe the relevant dimensions of the everyday residence and university context as represented in the students' narratives. For both analytical readings, ethnographic semantics (Spradley 1979) was employed, as it extends the reconstruction of mundane domains of action and interpretation into an analysis of cultural themes.

Being interested primarily in domains, categories, and themes, the interaction of the focus groups was rather instrumental towards facilitating detailed and rich accounts. This was done mainly among students, evoking their systems of relevancies concerning the issues discussed. We did not explicitly analyze the group discussions in terms of their structural properties, however, as the students explicate their experiences and views they account in varying degrees for the presence and anticipated reaction of the other students. The focus group thus constitutes a temporary "tiny public" (Fine and Harrington 2004) that is, indeed, an ethnographic context of its own (cf. Wilkinson 2011:173). An interaction is generated that is not part of the everyday contexts of the students and which is characterized by the presence of a researcher who "injects" issues into the discussion, who is instrumental in framing, establishing, maintaining, and dissolving the interaction situation, and whose presence-as a relative non-member of the students' lifeworld and as someone with specific gender, age, "ethnic," academic, et cetera attributes-may suggest specific forms of communication and interaction. But, as far as the focus group as temporal and situated accomplishment is based on habitualized practices-and as far as these practices are not exclusively competencies for focus group participation-it does allow for inferences as to what kind of cultural practices and standards, for example, the use of population categories, are externalized by the students in their everyday lives and to what extent these are enacted. The next section offers insights into this question by presenting some of the narratives of students living in residences on the main campus.

\section{Findings}

According to the data, race and ethnicity remain important identity markers to students currently enrolled at the institution. Almost every response concerning racial or ethnic identification was introduced with a phrase indicating the given individual's pride in his or her racial identification. In the words of Tezovic, a Black male participant:

I'm Xhosa and I'm proud to be Xhosa. It's my identity.

Racial and ethnic identifications remain a fundamental concern for many students, and the history of the country ensures that it does not vanish 
into the background of social life. This identification with racially defined feelings of groupness is strong among both Black and White students. Responding to the charge of being descended from immigrants and thus not sufficiently African, Chomp, a White male participant, makes the following remark:

...what should we do? I was born here, but [I] feel like an alien.

It seems that a certain historical weight, a legacy of mutual violence, has affected the self-understanding of students to a great degree before they even arrive at university. It also seems that, when students arrive at university to start tertiary studies, racial and ethnic identifications are internalized to the extent that many expect to be staying with others from their own racial and ethnic background in the residence that is to be their home for the next few years. The loss of this homogeneity, which correlates with a weakening of the dominant culture of their biographical background, is lamented by various students, including Mr. S, who experiences the effects of mandatory integration as a process of sweeping change that makes just one more politically correct public arena out of a previously closed cultural safe-space:

...the hostel used to be part of your identity, now it's just a place to stay.

Although racial and ethnic enclaves remain, there is little outright hostility along these lines. Rather, a sense of understanding, empathy, and solidarity generally flourishes. In the absence of what uni- versity policy would define as integration, many students report positive tolerance. The now thoroughly multiracial and multi-ethnic character of the campus and especially the residences does, however, mean that minor clashes sometimes occur. Various occasions are reported, ranging from dissonance in sexual, sanitary, and social behavior to occasional reports of verbal and physical altercations. It does seem as though the most turbulent years of the institution's transformation into a multicultural institute of higher learning is behind it, as mainstream acceptance of multiculturalism is the norm among many students and any behavior infringing on that understanding is seen as radical and deviant from both White and Black students' perspectives. Be that as it may, boundaries along ethnic and racial identifications remain salient in everyday life and "us and them" issues strongly inform student discourse, especially when it comes to issues regarding racially mixed residences and the ways in which students perceive top management's policies in this regard. Black and White students are united in the stance that university administration is implementing far-reaching policies without-or only marginally-involving the students in the process, and with little positive management of the consequences of these policies. A White male participant, Mr. Gericke, laments the enduring self-segregation of students in his residence, even though the intake of new students is strictly managed to ensure diversity:

It's actually become like the old days now, you know. The Black guys live almost exclusively in one part of the building and the White guys in another.
A Black female participant, Sira, echoes this sentiment:

I know me as a Black person, I have my own culture, and I'm Xhosa. I'm going to do things this way and obviously won't click all the time with Sotho people because they have their own ways, and also when it comes to English and then Afrikaans people; you just get the feeling that it will never work. In the hostel, I tolerate them. It's not like we like each other, we just tolerate each other. You keep your distance, I keep my distance.

Such feelings of tolerant distance reflected in these comments are not directed at members of other racial or ethnic categories as such; rather, this skeptic stance is shaped by the perception of the way in which university management has implemented integration. Though there are accusations of resistance to change and unwillingness to cooperate directed towards outgroups, such as Ntombi's opinion that

\section{...some races are resistant to changes,}

or that of Mr. Gericke when he says

...the Black guys don't want to adjust. They disobey the rules and we have to change,

students readily agree that

...you get the feeling that it's all about numbers. This forced integration only hinders any real progress,

as Mr. S puts it. Sira agrees, further revealing the students' confusion and frustration with a policy that many see as causing unnecessary friction:
I don't know whether they want us to stay together or accept each other in any way because they just come and put Black people in White hostels and White people in Black hostels, and then they leave it like that. They don't research to see what happens in three months. It's just that thing they do, and they leave it like that.

Indeed, outside of the institutionally managed context of the residence, conflict between members of different racial and ethnic categories does not present itself as a serious issue. Certain cultural practices do conflict with each other, but where this is the case, the issue is usually resolved without the need for violence or institutional involvement. Rather, the main point of contention present is the question of Afrikaans as an official language of the University. This issue sharply divides the students that participated in this study. There are those who feel that English should be the sole language and that the University should be a linguistically neutral zone. They argue that as they leave their mother tongue at home, Afrikaans-speaking students should do the same. This view can get quite impassioned, as is expressed by Gabby, a Black female participant, when she says:

Let them learn in Afrikaans so they can get stuck here in the Free State.

A vast majority of participants see the bilingual facet of the University as unfair, and call for one medium of instruction, based not on certain ethnically or racially underpinned cultural outlooks, but on neutral and mutually beneficial concerns. Meeting each other midway in such a fashion seems like an easy 
solution, but a minority feels just as strong about their right to keep learning in Afrikaans, arguing that their rights would be infringed upon if the language was to be taken away. The third opinionated group feels that Afrikaans can stay, but that equal recognition should then be given to other indigenous languages, or at least Sotho, which, along with English and Afrikaans, is one of the most widely spoken languages in the region. ${ }^{3}$

There is also little social intercourse between Black and White students off campus, with it being common knowledge that there are different bars and nightclubs frequented by the individuals belonging to the various racial groups. To some this state of affairs comes naturally, while the high degree of social segregation at the University engenders a shocking and traumatic experience for others. Many students that hail from other parts of the country, especially those from the larger, more liberal metropolitan areas, find this state of affairs quite strange, with many theorizing that it might be a regional phenomenon. Tezovic goes on to describe the situation thus:

I stopped going to certain places. I went once or twice and got funny stares and I realized I'm not meant to be here. I stopped going out to certain places.

The measure of this social segregation tends to vary among demographical subsets. A study carried out in the U.S. discovered various differences in racial identity between individuals with different social

${ }^{3}$ The University of the Free State recently adopted a new language policy. English will now be the sole formal medium of
education, while support will be offered in Afrikaans, Tswana, and Sotho, the three most widely spoken indigenous languages in the University (Marais 2016). backgrounds, noting, for example, that individuals from more cosmopolitan backgrounds tend to diffuse racially tense scenarios more successfully (Tatum 2004). This hypothesis was supported by our findings, with various participants who came here from other metropolitan areas regarding many of the most controversial race-based matters to be a regional issue. Chomp, for instance, said the following:

In Cape Town, you don't see this. I went to school with Black guys and when I came here, it was like, wow. I think it's a Bloemfontein thing.

This example can be compared to Tezovic's story about coming here from the Eastern Cape and has a lot in common with Sir's story of a White school friend becoming absorbed in what he calls "Bloemfontein's racist subculture":

This guy was English, like proper English, but when we came here, after a few months, he was talking Afrikaans and we almost never see each other anymore.

Almost identical tales were told by female participants. Following this course of investigation may shed light on differences between the attitudes of students from rural backgrounds and those whose roots are in the city, an important distinction within the Zulu, Sotho, and Afrikaans communities in particular. Various cases of lifelong interracial friendships crumbling after the first few months in Bloemfontein were recorded.

These regional, as well as rural-urban differences intersect with divides in the ethnic realm, compli- cating the issue of integration and segregation even further. According to Sir, another Black participant:

Two Sotho guys are tight, but a Sotho and a Xhosa guy are not as tight.

A similar situation was seen in the social behavior of Afrikaans- and English-speaking White students. Thus, an individual's racial and ethnic identification currently plays a major role in the patterns of social contact that person is likely to follow during his or her tenure as a student at the University of the Free State. Many students also believe that management's closure of the residence taverns has worsened the situation as Black and White students who previously socialized together in the same residence now frequent different spots in town where segregationist patterns remain well-established. With the few racially diverse arenas of social contact eradicated by management policies designed to curb substance abuse, ethnic and racial identification, and the associated indirect self-segregation of students through choices in the leisure domain further contribute to the enactment of boundaries along ethnic and racial categories, a phenomenon which is very much alive at the University. As Mr. Gericke, a White male participant, points out:

...so we don't really mix. The thing is, we don't have that much in common. Take our languages, for instance, you associate with those you share something with. It's not a racist thing.

While focusing on all this, it is important to keep in mind that race, though an important factor, should not be considered as necessarily always being the most salient phenomenon. Various other factors, like social and financial status, may carry as much weight in the social integration process of especially senior undergraduate students. The data yielded by our research supported this view in the sense that where racial integration is implemented in residences, there is often a vast gap in socio-economic status that largely correlates with race. In this regard, Chomp, a White male participant, had the following to say:

The thing is, these kids come from homes where they don't have a lot of money for socializing. They can't go to the places or do the things the White guys do because they don't have the money. This makes it even harder to integrate.

All of South Africa's universities are racially integrated today, but one needs only take a walk across campus to see that the reality at the micro-level does not reflect the expectations of the macro-level. As Crozier and Davies (2008) said, "the trouble is they don't mix." In a society like South Africa, where racial separation and enmity have long been the dish of the day, it is important to explore the contemporary self-segregation of students, as well as the behavior of those who form the exception to this rule. This should, however, not be done with any political outcomes in mind, but in the spirit of uncovering the meaningful experiences of the people affected by these processes on a daily basis. All the participants were familiar with the multiracial and multi-ethnic reality of contemporary South African campuses and had been exposed to situations involving culturally diverse actors on various occasions since enrolment at the institution. One area where progress 
has been made is in perceptions and the emphatic understanding of members of other population categories. Even if voluntary social contact remains rare, incidences of racism and other forms of prejudice based on race or ethnicity have declined significantly. Since the residence integration policy has been put in place, students have been forced to move beyond their comfort zones and experience unprecedented levels of physical and social proximity to a vast array of individuals differing from themselves in factors such as race, ethnicity, culture, and religion.

\section{Conclusion}

Apart from the dynamics of relations between members of different ethnic and racial categories at the University of the Free State, the findings of this study shed light on the status of education as an institution in South Africa. Until 1994, student racial segregation from pre-school to post-graduate level was official government policy, and this arrangement continues to impact on lived realities today. To summarize, the findings of this study include that institutional desegregation is not integration and that the mixing of students belonging to different ethnic and racial categories without sufficient structural and administrative support, along with an experienced investment in the process by the students themselves, tends to encourage self-segregating practices instead of mutually shared experiences. Without the inner structures and meaning-making processes of both the institution and members of all backgrounds undergoing fundamental modifications, the arbitrary mixing of different racial categories in classrooms and residences will continue to be risk-factors with regard to the intended outcome of such mixing. This leads us to consider the importance of successful multicultural educational practices as paramount to the successful integration of South African graduate students into the multicultural world of business and post-educational social life. When combined with a sensitive understanding of the ethnicized and racialized histories and relationships in any given society, multicultural education is one of the most powerful assets any student can have (as opposed to experiences of haphazard methods of simple desegregation).

The situation seems to be most tense in those male residences that have seen a significant Black minority moving in since 2008. The reasons for this appear to be myriad. According to the narratives, White minorities in Black residences tend to move out after short periods of time, while Black students moving into traditionally White residences stay there. This may be due to a range of factors, and, apart from "White flight," one of the most important is socio-economic status. Many of the Black students simply cannot afford private accommodation and thus choose to stay where management places them, even if a certain degree of discomfort is involved. This situation results in the illusion that Black students are "taking over" White residences, while traditionally Black residences are not transforming at all. This sentiment, along with certain actions taken by management, has resulted in a sense of alienation, especially in White male students in historically White residences.

The UFS's integration policy is made significantly harder to implement through the stubborn existence of somewhat antiquated residence-specific traditions and value systems, which are slowly but surely starting to evolve as the residences that spawned these systems see their population change. Both Black and White participants report fundamental changes in residence traditions and patterns of behavior and interaction since the advent of mixed-raced residences, and various erstwhile practices, many of which would be seen as highly exclusive and alienating to outside observers, have been replaced by more inclusive, culturally neutral forms of behavior. Once again these changes have been most dramatic in the traditionally White male residences involved in the study. Many of these residences had long histories of physical initiation rituals and traditions reminiscent of military practice which in some cases do stretch back to the time of military conscription under the National Party government and its embeddedness in the Afrikaner nationalist project.

The weakening of these practices has, indeed, brought about change in how a residence at the Uni-

\section{References}

Aldrich, Howard E. and Roger Waldinger. 1990. “Ethnicity and Entrepreneurship." Annual Review of Sociology 16:111-135.

Alonso, Ana María. 1994. “The Politics of Space, Time and Substance: State Formation, Nationalism, and Ethnicity." Annual Review of Anthropology 23:379-405.

Alsheh, Yehonatan and Florian Elliker. 2015. "The Art of Becoming a Minority. Afrikaner Re-Politicisation and Afrikaans Political Ethnicity." African Studies 74(3):429-448. versity of the Free State is defined. Changing demographics and an increasingly top-down attitude from management, albeit one that seeks to further the academic and social mission of the institution, have led to campus residences becoming less and less bastions of "identity and culture," where one's self-understanding is shaped and cultural capital is acquired, and more and more places of residence and study primarily. This move from an emphasis on the collective to a focus on the individual is one that garners strong opinions from students, both for and against the process. There is, however, an emerging trend that accepts the changes, grudgingly in the most extreme cases, but willingly nonetheless. Slowly but surely a paradigm shift is taking place among students. The hardcore hangers-on of the fraternity and sorority type residence dynamic is slowly giving way to a more modern attitude of live and let live, which accepts the importance of individual academic success as a factor that takes precedence of the social identity provided by membership of a given residence. 
Berger, Peter L. and Thomas Luckmann. 1966. The Social Construction of Reality: A Treatise in the Sociology of Knowledge. Garden City, NY: Doubleday.

Bishop, John et al. 2004. "Reviewing a Decade of Change in the Student Culture." Journal of College Student Psychotherapy 18(3):3-30.

Bohnsack, Ralf. 2004. "Group Discussions and Focus Groups." Pp. 214-221 in A Companion to Qualitative Research, edited by U. Flick. London, Thousand Oaks, New Delhi: Sage.

Bowker, Geoffrey C. and Susan Leigh Star. 2000. Sorting Things Out: Classification and Its Consequences. Cambridge, London: MIT Press.

Brown, Rupert and Katy Greenland. 2005. “Acculturation and Contact in Japanese Students Studying in the United Kingdom." Journal of Social Psychology 145(4):373-389.

Brown, Rupert and Hanna Zagefka. 2002. "The Relationship between Acculturation Strategies, Relative Fit and Intergroup Relations. Immigrant-Majority Relations in Germany." European Journal of Social Psychology 32(2):171-188.

Brubaker, Rogers. 2002. “Ethnicity without Groups.” Archives Européennes de Sociologie / European Journal of Sociology 43(2):163-189.

Brubaker, Rogers. 2009. "Ethnicity, Race, and Nationalism." Annual Review of Sociology 35:21-42.

Brubaker, Rogers and Frederick Cooper. 2000. “Beyond ‘Identity."' Theory and Society 29:1-47.

Brubaker, Rogers and David D. Laitin. 1998. “Ethnic and Nationalist Violence." Annual Review of Sociology 24:423-452.

Brubaker, Rogers, Mara Loveman, and Peter Stamatov. 2004. “Ethnicity as Cognition." Theory and Society 33(1):31-64.

Calhoun, Craig J. 1993. "Nationalism and Ethnicity." Annual Review of Sociology 19:211-239.

Chavous, Tabbye M. 2005. “An Intergroup Contact-Theory Framework for Evaluating Racial Climate on Predominantly
White College Campuses." American Journal of Community Psychology 36(3):239-257.

Cole, Elizabeth R. and Tiffany Yip. 2008. “Using Out-Group Comfort to Predict Black Students' College Experiences." Cultural Diversity and Ethnic Minority Psychology 14(1):57-66.

Collins, Randall. 2004. Interaction Ritual Chains. Princeton Princeton University Press.

Crozier, Gill and Jane Davies. 2008. “'The Trouble Is They Don't Mix': Self-Segregation or Enforced Exclusion?" Race, Ethnicity and Education 11(3):285-301.

Dietz, Franziska et al. 2005. "Conflicting Values and Their Impact on Learning." European Journal of Psychology of Education 20(3):259-273.

Dumont, Kitty and Burger van Lill. 2009. "Dominant and Non-Dominant Groups' Responses to Social Change: The Economic Transformation Process in South Africa." South African Journal of Psychology 39(4):432-447.

Ehrmann, Nicholas. 2007. “From the Ghetto to the Ivory Tower: Gendered Effects of Segregation on Elite-College Completion" Social Science Quarterly 88(5):1392-1414

Fine, Gary A. 2010. “The Sociology of the Local: Action and It Publics." Sociological Theory 28(4):355-376.

Fine, Gary A. and Brooke Harrington. 2004. “Tiny Publics: Small Groups and Civil Society." Sociological Theory 22(3):341-356.

Foster, Robert J. 1991. "Making National Cultures in the Global Ecumene." Annual Review of Anthropology 20:235-260.

Frable, Deborrah E. 1997. "Gender, Racial, Ethnic, Sexual, and Class Identities." Annual Review of Psychology 48:139-162.

Frank, Arthur W. 2012. “Practicing Dialogical Narrative Analysis." Pp. 33-52 in Varieties of Narrative Analysis, edited by J. F. Gubrium and J. Holstein. London: Sage.

Gumperz, John J. 1982. Discourse Strategies. Cambridge: Cambridge University Press.
Gwele, Nomthandazo S. 2002. “Racial Relations in Selected Faculties in English Language Historically White Universities in South Africa." Society in Transition 33(1):134-151.

Harrison, Faye V. 1995. “The Persistent Power of 'Race' in the Cultural and Political Economy of Racism." Annual Review of Anthropology 24:47-74.

Kane, Emily W. 2000. "Racial and Ethnic Variations in Gender-Related Attitudes." Annual Review of Sociology 26:419-439.

Klugman, Barbara. 2008. "Race, Class, Gender and SexualityChallenges for an Inclusive Citizenship." South African Review of Sociology 39(2):218-231.

Knoblauch, Hubert. 1995. Kommunikationskultur: die kommunikative Konstruktion kultureller Kontexte. Berlin, New York: Walter de Gruyter.

Kotze, P. Conrad. 2017. “On the Nature of an Integral Sociology: An Exploration in Theory and Practice." Qualitative Sociology Review 13(1):246-269.

Kotzé, Hennie J. 1993. "Overlapping Values of the South African Elite: Applying an Adapted Wilson-Patterson C-Scale." South African Journal of Sociology 24(1):1-8.

Kriel, Mariana. 2003. "Approaches to Multilingualism in Language Planning and Identity Politics: A Critique." Society in Transition 34(1):159-177.

Liem, Joan H. and Gemima R. St. Louis. 2005. “Ego Identity, Ethnic Identity, and the Psychosocial Well-Being of Ethnic Minority and Majority College Students." Identity 5(3):227-246.

Marais, Madre. 2016. UFS Gets New Language Policy. News24. Retrieved June 08, 2016 (http://www.news24.com/SouthAfrica/ Local/Express-News/ufs-gets-new-language-policy-20160322).

Møller, Valerie. 1996. "Life Satisfaction and Expectations for the Future in a Sample of University Students: A Research Note." South African Journal of Sociology 27(1):16-26.

Morgan, David L. 1988. Focus Groups as Qualitative Research. Newbury Park, London, New Delhi: Sage.
Nagel, Joane. 2000. "Ethnicity and Sexuality." Annual Review of Sociology 26:107-133.

Olzak, Susan. 1983. “Contemporary Ethnic Mobilization.” An nual Review of Sociology 9:355-374

Omi, Michael and Howard Winant. 1994. Racial Formation in the United States: From the 1960s to the 1990s. New York: Routledge.

Peens, Michelle. 2012. “Racial Remains in a Company Town? Iscor Houses and the Appearance of Race in Contemporary Newcastle." South African Review of Sociology 43(1):23-40.

Piper, Laurence et al. 2005. “'They Don't Know Who's Who in the Zoo': The Ironic Failure of State-Managed Racial Desegregation in the Government Village of Oribi, Pietermaritzburg." Society in Transition 36(1):97-112.

Prinsloo, Rachel. 1996. "Studying the Cleavaged Society: The Contributions of Eric Hobsbawm." South African Journal of Sociology 27(1):26-34.

Quillian, Lincoln. 2006. “New Approaches to Understanding Racial Prejudice and Discrimination." Annual Review of Sociology 32:299-328

Reckwitz, Andreas. 2001. "Multikulturalismustheorien und der kulturbegriff: vom Homogenitätsmodell zum Modell kultureller Interferenzen." Berliner Journal für Soziologie 2:179-200.

Reskin, Barbara. 2012. “The Race Discrimination System." Annual Review of Sociology 38:17-35.

Sanders, Jimmy M. 2002. “Ethnic Boundaries and Identity in Plural Societies." Annual Review of Sociology 28:327-357.

Sang, David, Lei Wang, and Xue Zheng. 2004. "Acculturation and Subjective Well-Being of Chinese Students in Australia." Journal of Happiness Studies 5:57-72.

Schütz, Alfred. 2004. Der sinnhafte Aufbau der sozialen Welt: eine Einleitung in die verstehende Soziologie. Konstanz: UVK.

Schütz, Alfred and Thomas Luckmann. 1989. The Structures of the Life-World, vol. 2. Evanston: Northwestern University. 
Sennett, Justin et al. 2003. "Adjustment of Black Students at a Historically White South African University." Educational Psychology 23(1):107-116.

Silverman, David. 2011. Interpreting Qualitative Data: A Guide to Principles of Qualitative Research. Los Angeles, London, New Delhi: Sage.

Spradley, James P. 1979. The Ethnographic Interview. New York, Chicago, London: Holt, Rinehart \& Winston.

Steyn, Carly and Hennie J. Kotzé. 2004. "Work Values and Transformation: The South African Case, 1990-2001." Society in Transition 35(1):145-164.

Tatum, Beverly D. 2004. "Family Life and School Experience; Factors in the Racial Identity Development of Black Youth in White Communities." Journal of Social Issues 60(1):117-135.

Taylor, Jared. 2011. White Identity: Racial Consciousness in the 21 ${ }^{\text {st }}$ Century. New Delhi: New Century Books.

Vahed, Goolam. 2001. "'There Is Plenty of Play Left in South Africa's Race Game': Race, Cricket and Nation in Post-Apartheid South Africa." Society in Transition 32(2):260-276.

Venter, Dawid. 1998. "Silencing Babel? Language Preference in Voluntary Associations-Evidence from Multi-Cultural Congregations." Society in Transition 29(1/2):22-39.
Wale, Kim and Don Foster. 2007. "Investing in Discourses of Poverty and Development: How White Wealthy South Africans Mobilise Meaning to Maintain Privilege." South African Review of Sociology 38(1):45-69.

Warr, Deborah J. 2005. “'It Was Fun, But We Don't Usually Talk about These Things': Analyzing Sociable Interaction in Focu Groups." Qualitative Inquiry 11(2):220-225.

Webster, Edward C. 1999. "Race, Labour Process and Transition: The Sociology of Work in South Africa." Society in Transition 30(1):28-42.

Wilkinson, Sue. 2011. “Analysing Focus Group Data." Pp. $168-$ 184 in Qualitative Research: Issues of Theory, Method and Practice, edited by D. Silverman. Los Angeles, London, New Delhi Sage.

Williams, Robin M., Jr. 1994. "The Sociology of Ethnic Conflicts: Comparative International Perspectives." Annual Review of Sociology 20:49-79.

Yinger, J. Milton. 1985. "Ethnicity." Annual Review of Sociology 11:151-180

Zubrinsky Charles, Camille. 2003. "The Dynamics of Racial Residential Segregation." Annual Review of Sociology 29: $167-207$ 